
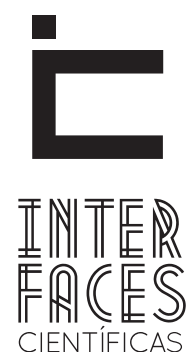

EDUCAÇÃO

\title{
REPENSANDO AS PRIISÕES DE GÊNERO A PARTIR DE UMA “VISITA İNTIMA": DO ENREDO FÍLMICO PARA A VIDA
}

Jesana Batista Pereira

\section{RESUMO}

Este artigo procura refletir sobre uma das atividades desenvolvidas na disciplina Seminários Temáticos I, ofertada para alunas (os) do curso de Serviço Social, na Universidade Tiradentes e é desenvolvida a partir da articulação de três eixos temáticos: Cultura e Subjetividade; Gênero e Raça/Etnia e Assistência Social, Pobreza e Exclusão Social. Apesar de geralmente termos utilizado os mesmos textos para discussão, realçando a interlocução entre as temáticas focalizadas, algumas (uns) alunas (os) sentem dificuldade em apreender a correlação existente entre o pertencimento a determinado gênero e grupo étnico, e o processo de construção das subjetividades múltiplas na cultura contemporânea. A exibição do curta metragem Visita Íntima foi utilizada para identificar o processo de construção subjetiva das (os) alunas (os) acerca do que é ser homem e do que é ser mulher e de que papéis sociais e sexuais são atribuídos cultural-
Márcia Santana Tavares "

mente a homens e mulheres. Para tanto, elaboramos quatro questões que deveriam ser respondidas após acessarem em seus computadores o filme, no site www.portacurtas.com.br. Apesar de terem assimilado do ponto de vista teórico que não há uma essencialidade no desempenho dos papéis sexuais e sociais, as construções subjetivas das alunas demonstram que não seriam capazes de encenar outro drama, uma vez que naturalizam os papéis sexuais e sociais atribuídos culturalmente a homens e a mulheres. Constata-se que tanto as mulheres do documentário quanto as espectadoras, reafirmam o ethos do amor romântico, validado pela divisão desigual dos papéis amorosos entre homens e mulheres.

\section{PALAVRAS-CHAVE}

Gênero. Pedagogia. Narrativa Fílmica. Subjetividade. 


\section{ABSTRACT}

This article seeks to reflect on one of the activities developed in the Thematic Seminars I, offered to students of Social Service at the University Tiradentes and is developed from the combination of three main themes: Culture and Subjectivity; Gender and Race/Ethnicity and Social Assistance, Poverty and Social Exclusion. Although generally use the same texts for discussion by highlighting the interaction between the themes focused, some students find it difficult to grasp the correlation between membership of a particular ethnic group and gender, and the construction process of multiple subjectivities in contemporary culture. The short film Intimate Visit was used to identify the process of building students' subjective about what it is being a man and being a woman, and that social and sexual roles are culturally assigned to women and men. Therefore, we prepared four questions that should be answered after accessing the movie on their computers, the website www.portacurtas.com.br. Despite having assimilated the theoretical point of view that there is no essence in the performance of social and sexual roles, the subjective constructions of students demonstrate that they would not be able to stage another drama once naturalize social and sexual roles assigned to men and women culturally. It is appears that women in the documentary as the spectators, reaffirm the ethos of romantic love, validated by the unequal division of romantic roles between men and women.

\section{KEYWORDS}

Gender. Pedagogy. Film Narratives. Subjectivity.

\section{RESUMEN}

Este artículo intenta reflexionar sobre una de las actividades desarrolladas en la asignatura seminarios temáticos, ofrecida al curso de los alumnos (as) de Servicio Social, en la Universidad Tiradentes y se desarrolla a partir de la combinación de tres temas principales: cultura y subjetividad; Género y raza/Origen Étnico y Asistencia Social, la pobreza y la exclusión Social. Aunque generalmente hemos usado los mismos textos para la discusión, destacando la interacción entre los temas, algunos (as) alumnos (as) sienten dificultad en aprender la correlación que existe entre la pertenencia a determinado sexo y grupo étnico y el proceso de construcción de subjetividades múltiples en la cultura contemporánea. El cortometraje Visita Íntima se utilizó para identificar el proceso de construcción subjetiva de los alumnos (as) sobre lo que es ser hombre y lo que es ser mujer, y qué papeles sociales y sexuales son culturalmente asignados a hombres y mujeres. Para ello, hemos desarrollado cuatro preguntas que deben responderse después de acceder por sus ordenadores a la película en el sitio www. portacurtas.com.br. Aunque ellos asimilaron desde el punto de vista teórico que no hay una esencialidad en el desempeño de papeles sociales y sexuales, las construcciones subjetivas de las alumnas demuestran que no serían capaces de escenificar otro drama, una vez que naturalizan los papeles sexuales y sociales asignados culturalmente a hombres y mujeres. Se observa que tanto las mujeres del documental como las espectadoras, reafirman el ethos del amor romántico, validado por la desigual división de roles románticos entre hombres y mujeres.

\section{PALABRAS CLAVE}

Género. Pedagogía. Narrativa Fílmica. Subjetividad. 
[...] o cinema nos convida a reflectir sobre o imaginário da realidade e sobre a realidade do imaginário" (EDGAR MORIN).

\section{REVISITANDO CENAS}

Visita Íntima é um curta metragem produzido em 2005 e dirigido por Joana Nin. Através de depoimentos de companheiras de presidiários, somos instigados a percorrer a saga de "príncipes" e "princesas" que engendram suas histórias de amor, dando sentido a vidas solitárias, áridas e imperfeitas, nas quais o amor é cultivado como um bálsamo, possibilidade de devir, pois, como argumenta uma das mulheres entrevistadas, "se você não tiver um amor, você não conquistou nada" e não terá "uma história para contar".

Para os homens, o amor é tido como redenção para os erros cometidos. Daí porque, como declara um dos presos em carta para a mulher amada: "Aqui princesa! Logo, logo, três coisas farão parte de nossa relação - eu, você e nosso amor. Beijos molhados de quem não consegue viver um minuto sem você". Neste sentido, "para o sexo, o melhor homem que tem é o que tira cadeia, o homem mais gostoso, o homem mais carinhoso[que] quando sair vai fazer agente feliz". Para um final feliz, é preciso casar na Igreja, bonita, maquiada e vestida de noiva, finalmente "livre, porque por enquanto estou presa com ele". Dessa forma, este amor é "para toda a vida, até a morte, por exemplo". E, portanto, "se minha alma valesse para alguma coisa, eu faria negócio para ele sair. 0 meu único objetivo é ir até o fim".

Este artigo procura refletir sobre uma das atividades desenvolvidas na disciplina Seminários Temáticos I, ofertada para alunas (os) do curso de Serviço Social, na Universidade Tiradentes e é desenvolvida a partir da articulação de três eixos temáticos: Cultura e Subjetividade; Gênero e Raça/Etnia e Assistência Social, Pobreza e Exclusão Social. Apesar de geralmente utilizarmos os mesmos textos para discussão, realçando a interlocução entre as temáticas focalizadas, algumas (uns) alunas (os) sentem dificuldade em apreender a correlação existente entre 0 pertencimento a determinado gênero e grupo étnico e, o processo de construção das subjetividades múltiplas na cultura contemporânea e sua transversalidade no desenho e implementação de políticas sociais, em particular, a assistência social e seus programas de transferência de renda. Para elas (eles) a disciplina é vista como um pacote de "três em um", como assim a denominam, ou seja, três professoras apresentam leituras variadas sobre os temas abordados, o que sugere a idéia de uma superposição de tarefas, sem aparente aplicabilidade prática no futuro exercício da profissão. Desde o primeiro semestre letivo de 2007, temos procurado imprimir maior dinamicidade à disciplina, adotando uma metodologia mais interativa, através da discussão de artigos científicos, reportagens publicadas em revistas comerciais e jornais, realização de relatos de experiência, trabalhos de grupo, oficinas temáticas e cine-fóruns, bem como audição de músicas do cancioneiro popular, seguida de leitura e interpretação das letras a partir de uma perspectiva de gênero. A opção por tais caminhos metodológicos veio acompanhada da necessidade de também projetar um novo desenho às formas de avaliação, desenvolvidas através da elaboração de portfólios, jornais e cartilhas, apresentação de dinâmicas, teatro de marionetes ou roteirização e dramatização de fatos/acontecimentos cuja interpretação se fundamente no entrelaçamento dos eixos temáticos trabalhados na disciplina.

A exibição do curta metragem Visita Íntima foi utilizado para identificar o processo de construção subjetiva das (os) alunas (os) acerca do que é ser homem e do que é ser mulher e, de que papéis sociais e sexuais são atribuídos culturalmente a homens e mulheres. Para tanto, elaboramos quatro questões que deveriam ser respondidas após acessarem em seus 
computadores o filme, no site www.portacurtas.com. br. As questões formuladas foram as seguintes: 1) Em termos de gênero, quais os tipos de papéis sexuais essas mulheres se atribuem 2) Quem vocês acham que está mais encarcerado, elas que estão livres ou eles que estão presos? 0 que isso tem a ver com as construções subjetivas acerca do ser homem/ser mulher? 3) O que você faria se estivesse no lugar delas?

Cabe esclarecer que este artigo tomou a imagem fílmica não na perspectiva de uma pesquisa sobre imagens, mas com imagens, isto é, aqui pretendemos realçar o filme como espaço imaginário, ressaltando a característica antropológica da imagem fílmica, onde personagens, enredos, desenham uma recriação da realidade, de seus atores encenados na vida social e mitos reatualizados através do acontecimento do filme. Daí o filme, na qualidade de espaço imaginário ser entendido como "o conjunto das imagens que constitui o capital pensado do homo sapiens" (DURAND, 1989, p. 14).

Afinal, os signos, no cinema, não são signos lingüísticos, mesmo quando sonoros ou vocais. Por isso o cinema, como pondera Deleuze, traz uma "matéria movente" que exige uma nova compreensão das imagens e dos signos. 0 autor lembra ainda que, se estivermos fazendo pesquisa sobre imagens, estamos fazendo também pesquisa sobre idéias. Neste sentido, reforça que, no cinema, "somos tomados numa cadeia de imagens [...], mas também somos tomados numa trama de idéias, que agem como palavras de ordem" (idem, p. 58).

Além disso, alerta Morin (1997), não podemos ignorar a "situação estética" experimentada pelo expectador, esta situação remete a um estado de "dupla consciência”, muitas vezes despercebida, qual seja, "a ilusão da realidade é inseparável da consciência de que ela é realmente uma ilusão, sem que, no entanto, esta consciência destrua o sentimento de realidade" (Morin, 1997, p. 11-17).
Por outro lado, no senso comum, as representações elaboradas sobre as diferenças entre os sexos ainda permanecem calcadas na fisicalidade, contribuindo para a naturalização de outras tantas diferenças entre homens e mulheres, ou seja, definindo comportamentos, percepções, atitudes, padrões de expressão da afetividade, apropriação de espaços e condutas sexuais consideradas próprias para homens e mulheres.

Observa-se, portanto, que a bipolaridade entre os sexos além de estar centrada nos corpos, anatômica e biologicamente diferentes, consiste em um produto social que se materializa a partir das relações sociais entre homens e mulheres. Isto quer dizer que as identidades sexuais não são inerentes ao sexo biológico, mas elaborações sócio históricas e culturais que variam de uma sociedade, época, classe social, raça, etnia e até mesmo de uma geração para outra. Em resumo, "mulheres e homens de qualquer sociedade não nascem prontos, mas são inventados pela família, escola, religião, cinema, novela, propaganda, música etc., que vão definir os papéis que cada um deve exercer nessa sociedade" (PEREIRA, TAVARES, OLIM, 2006, p. 135).

Da mesma forma, as práticas e representações sobre o amor variam de classe para classe e de gênero para gênero. Para as mulheres das classes populares, entre as quais se inserem as personagens do curta analisado, ocorre um acumpliciamento entre os valores duais que determinam os papéis masculino e feminino, na medida em que validam uma condição de docilidade, subalternidade e resignação, uma vez que carregam um olhar fatalista sobre a realidade. "0 destino da mulher é traçado à sua revelia, sua autoimagem conduzida pelo homem. Casamento é sinônimo de tutela, proteção, e ainda que assim não se configure, esta não cogita uma separação [...]" (TAVARES, 2002, p. 55).

Tavares (2002), ao revisitar Tânia Dauster, destaca que, atualmente, a sexualidade da mulher é exercitada livremente, mas nem tanto, pois permanece subor- 
dinada metaforicamente ao amor. Já com o homem, isso não acontece, uma vez que sua prática sexual é desvinculada desse sentimento. Tais padrões sociais são validados para a construção da subjetividade individual e, apesar de vivermos em uma época em que existem múltiplos espaços simbólicos de possibilidade de construção de individualidades, paradoxalmente, modelos arcaicos de relação entre os sexos convivem lado a lado com novos comportamentos modelizadores e atitudes.

Neste sentido, Lipovetsky (2000, p. 36-37) pondera que, embora em nossos dias haja explicitação da libido feminina, não implicando necessariamente uma referência ao grande amor, não significa que as diferenças das mulheres em relação aos homens no campo dos afetos foram extintas. Nas palavras do autor: "O erotismo feminino continua a se alimentar de significações e

\section{RECORRÊNCIAS: O QUE DIZEM AS “ALUNAS"}

A primeira pergunta formulada busca indagar sobre os tipos de papéis sexuais que as mulheres do documentário colocam para si mesmas. As alunas elaboram as seguintes interpretações:

\begin{abstract}
As mulheres se colocam como um instrumento de prazer, não só com o objetivo de satisfazerem os companheiros e de tornarem a vida deles mais alegre. Elas se sentem na responsabilidade de melhorar a vida de seus companheiros e para isso se empenham como podem.
\end{abstract}

Papel de companheiras que agüentam passar por humilhações, medos, preconceitos, privações. Estão presentes nas falas e nas maneiras e nas falas dessas mulheres os estereótipos de gênero, aprisionadas na concepção de dever e de submissão, [...] começando no entendimento que elas têm do ser mulher e do amor incondicional, que supera tudo, como uma delas mesmo relata: 'o amor é tudo, se você não tiver um amor, não tem nada.

[...] ela tem que dar carinho o tempo todo, e não deixá-lo triste, se doar o possível na relação sexual, [...], ou seja, a mulher se deixa levar como um objeto de manuseio que vive em função do homem. de imagens sentimentais. [...] Qualquer que seja a força da liberação sexual, as mulheres permanecem ligadas a um erotismo sentimental e se mostram menos colecionadoras que os homens". Em resumo, essa evidência sociológica atualiza atitudes e sentimentalidades calcadas no ethos do amor romântico.

Se o romantismo está ligado à ascensão da lógica burguesa de mundo e do individualismo como valor, o casamento arranjado deixa de ser o princípio fundamental do sistema de alianças, ao mesmo tempo em que abre espaço para o livre arbítrio na formação das parcerias amorosas. No entanto, este livre arbítrio é domesticado pela fusão entre o casamento e o amor, isto é, o ethos do amor romântico está alicerçado na eternização do sentimento amoroso circunscrito ao casamento, que tem como guardiã dos afetos a mulher.
[...] cada uma delas aprende a desempenhar o seu papel sexual como mulher, que não se limita apenas a suprir as necessidades sexuais, biológicas de seus parceiros, mas sim desempenhando seu papel de mulher que não pode, não deve abandonar seu homem diante daquela situação, [...] através de seu papel de companheira, refúgio, algo sobre o que seu companheiro pode alimentar esperança e confiança, além de essas mulheres ajudarem na construção dos planos desses homens para quando adquirirem liberdade.

Conforme evidenciam as assertivas, as alunas demonstram compreender, do ponto de vista teórico, que os papéis sexuais e sociais atribuídos são construções culturais e conseguem identificar os atributos presentes no enredo fílmico. A mulher é abnegada, companheira, que se doa e luta por amor, capaz de agüentar humilhações e privações para preservar o grande amor. Por isso mesmo, dotada de paciência e capacidade de perdão, refúgio no qual se resguarda o homem para renovar a esperança e confiança no futuro. 
Ao serem instigadas a compararem o encarceramento dos companheiros no presídio e de suas mulheres extramuros, as alunas endossam o caráter prisional que os valores sociais exercem sobre as construções subjetivas de homens e de mulheres, pois consideram que essas mulheres estão mais presas em virtude de estarem impedidas de conviverem com o grande amor. Conforme respondem:

[...] elas pagam as conseqüências de um 'amor bandido', um 'amor encarcerado', privando-se da companhia diária de seus companheiros, tendo que superar a ausência dos seus amados em datas importantes, como Natal, aniversário, nascimento dos filhos entre outros. [...] Elas vivem em companhia do medo, da incerteza e da esperança.

Elas estão mais encarceradas do lado de fora do que eles que estão presos, já que elas têm que cumprir regras impostas para serem esposas aceitas pela sociedade.

O encarceramento no filme é exclusivo dos presos, uma vez que as mulheres cumprem semanalmente a rotina de visitar seus companheiros como uma forma espontânea, nada está obrigando-as a cumprir com essa rotina, elas fazem porque gostam.

É fato que as mulheres que estão encarceradas, poucas têm visita íntima, mas no caso dos homens, a maioria tem companheiras que os visitam frequentemente e que são fiéis. Portanto, o ser humano mulher é mais dedicado ao afeto e ao carinho com seus companheiros, priorizando a fidelidade.

Neste jogo de comparações, as alunas entendem que a mulher só se liberta quando o homem cumpre a sentença e ganha liberdade. Ora, isto nada tem de espontâneo, essa mulher aprende que tem de viver ao lado de seu grande amor conforme sacralizado pela instituição do casamento. Nas adversidades deve permanecer a seu lado incondicionalmente. Ela se encontra extra-muro, mas presa á fidelidade. E se torna mulher que ama e é amada a partir do sacrifício e devotamento ao companheiro.

E se estivesse no lugar dessas mulheres, o que fa- riam? Esta foi a última indagação formulada às alunas. Vejamos o que respondem:

Ao refletirmos sobre esse amor que rompe barreiras nos colocamos no lugar dessas mulheres que lutam pela felicidade que está justamente no modelo de homem ideal (sensível, amoroso, atencioso, bom de cama, fiel), enfim, perfeito. Esse homem é raro e, se encontrarmos em um meio social 'livre', lutaremos com todas as forças pela sobrevivência desse amor e se por ventura esse amor for aprisionado (encarcerado), não mudará nada, permaneceremos amando.

Essas mulheres acabam fazendo o papel de um amor submisso. Sob minha visão elas estão apenas se reduzindo àquilo que the é permitido e estão condicionadas a isso, por mais que a situação jamais mude. Se eu estivesse no lugar dessas mulheres, a minha história não seria diferente de nenhuma delas, porque no final todas têm a mesma história, tudo por amor. Me submeteria a qualquer tipo de situação para estar com a pessoa amada, mesmo nas condições de constrangimento para ter uma visita íntima.

Expondo nosso comportamento perante a condição vivida pelas personagens do filme, continuaríamos com a mesma perspectiva apresentada por elas, pois quando amamos alguém de verdade, queremos o bem e estar com ele independente das circunstâncias, com esperança de que algum dia todo contratempo finde, podendo assim desfrutar juntos o amor que temos para dar.

Diante desse contexto é possível afirmar que a mulher sempre vai estar associada ao sentimento do amor Afinal, este quadro vem sendo construído e reafirmado de geração a geração. Logo, tudo nos leva a pensar que se estivéssemos no lugar daquelas mulheres, também agiríamos da mesma forma.

Bem, pelo visto as alunas não fariam diferente! Seguiriam o mesmo enredo, encenando os mesmos personagens da trama e reprisando as mesmas construções de gênero que essencializam os atributos femininos tais quais: a infinita capacidade de amar independente das circunstâncias, sacrifícios, humilhações, constrangimentos e privações, pois a mulher para ser amada tem que se fazer amar e isso só acontece através da doação ao outro. Tanto 
para as personagens do curta como para as alunas, a mulher só existe através do homem, nem que para isso tenham que transformar sapos em príncipes. É de se notar que o único homem da turma, em suas assertivas, demonstra, comodamente, que "isto não é um problema meu”. Fica evidente aqui que, no aprendizado do ser mulher, elas são submetidas a um cárcere emocional e afetivo - o ethos do amor romântico - que leva as alunas a renomearem o documentário: Amor e Esperança.

\section{REPRISE DE UM VELHO FILME}

Apesar de terem assimilado do ponto de vista teórico que não há uma essencialidade no desempenho dos papéis sexuais e sociais, as construções subjetivas das alunas demonstram que não seriam capazes de encenar outro drama, uma vez que naturalizam os papéis sexuais e sociais atribuídos culturalmente a homens e a mulheres. Dito de outra forma, as discussões feitas em sala de aula não provocaram mudanças na visão de mundo das alunas, quanto ao que pensam acerca do que é próprio ao homem e à mulher.

Constata-se que tanto as mulheres do documentário quanto as espectadoras, reafirmam o ethos do amor romântico, validado pela divisão desigual dos papéis amorosos entre homens e mulheres. A mulher permanece serva do culto ao amor, e responsável pelo sucesso da saga de seus príncipes desencantados, mesmo que para isso precisem esquecer que ela poderia viver outras sagas, representando personagens menos presos a esses antigos avatares. A despeito das discussões, as alunas continuam "presas sem correntes", apesar da possibilidade de múltiplas construções subjetivas conferidas pela sociedade contemporânea. Enfim, para as alunas a divisão sexual dos papéis afetivos está longe de ser abolida e, por isso não conseguem dissociar sexo e sentimento, nem tampouco a existência da mulher sem "um homem para chamar de seu".

É difícil tentar mudar um sistema de imagens que fundamenta vivências desiguais de sujeitos, no caso, mulheres e homens, uma vez que ficções arcaicas resistem a imperativos de ordem sócio-histórica. Isto mostra que movimentos sociais, como o feminismo, cujo baluarte é a equidade de gênero, não se mostra suficiente para estancar modelos arquetípicos duais. Talvez haja encantamentos regidos por outras lógicas, múltiplas e díspares, e porque não funcionais, que só a solidão do humano possa elucidar. 


\section{REFERÊNCIAS}

DURAND, Gilbert. As Estruturas Antropológicas do Imaginário. 1. ed. Lisboa: Editorial Presença, 1989.

LIPOVETSKY, Gilles. A Terceira Mulher: permanência e revolução do feminino. São Paulo: Companhia das Letras, 2000.

MORIN, Edgar. 0 Cinema ou o Homem Imaginário. Lisboa: Relógio D’Água Editores, 1997.

PEREIRA, Jesana Batista; TAVARES, Márcia Santana; OLIM, Maura Lúcia Santos de. “Gostaria de Ser Livre como as Flores e Plantas, pois são Livres para viver sem medo de errar”. Fragmenta: Revista Cientifica/Universidade Tiradentes. - v. VI, n. 8 -. Aracaju: Gutemberg, 2006, p. 131 - 141. (Edição Especial 45 anos).

TAVARES, Márcia. Pelas Lentes do Amor: um estudo sobre o cotidiano amoroso de camadas médias urbanas. Aracaju: Remar, 2002.

Visita Íntima. Direção de Joana Nin, 2005, (15 min.) Disponível em: http://www.portacurtas.com.br/Filme.asp?Cod=3223. Acesso em: 02 out 2008. 